\title{
Direct versus Indirect Explicit Methods of Enhancing EFL Students' English Grammatical Competence: A Concept Checking-based Consciousness-raising Tasks Model
}

\author{
Trang Thị Đoan Đặng ${ }^{1}$ \& Hương Thu Nguyễn ${ }^{2}$ \\ ${ }^{1}$ Marie Curie High School, Ho Chi Minh City, Vietnam \\ ${ }^{2}$ Hoa Sen University, Vietnam \\ Correspondence: Hương Thu Nguyễn, Hoa Sen University, Vietnam. E-mail: huong.nguyenthu@hoasen.edu.vn
}

Received: October 13, 2012 Accepted: October 23, 2012 Online Published: December 12, 2012

doi:10.5539/elt.v6n1p112 URL: http://dx.doi.org/10.5539/elt.v6n1p112

\begin{abstract}
Two approaches to grammar instruction are often discussed in the ESL literature: direct explicit grammar instruction (DEGI) (deduction) and indirect explicit grammar instruction (IEGI) (induction). This study aims to explore the effects of indirect explicit grammar instruction on EFL learners' mastery of English tenses. Ninety-four eleventh-graders were conveniently selected and randomly assigned into either the experimental group (EG) or the control group (CG). A pre-post tests design was used to collect the data. Before and after the treatment, the following tests were administered: rule analysis, grammar, and speaking. A delayed written test was given to both groups to assess students' retention of structure acquired; in addition, a questionnaire was provided to the EG to investigate their perception on the treatment. The results indicated that the EG significantly outperformed the CG in the analysis of grammar rules and the oral proficiency, except for the use of grammar structures in a pre-defined context. Convincingly, there was a positive correlation between the grammar rules and their subsequent use. This validates the cause and effect of grammar rules' acquisition and the use of them in receptive and productive stages. Also, the EG had favorable attitudes towards the instruction. This study may provide practical implications and techniques for improving EFL students' grammar performance in high schools in Vietnam.
\end{abstract}

Keywords: deduction, induction, pre-defined, subsequent, receptive, productive

\section{Introduction}

\subsection{Background of the Problem}

In the context of English teaching in most secondary and high schools in Vietnam, the two popular forms of grammar teaching are deduction and induction. Some teachers heavily depend on deductive grammar instruction while others apply inductive instruction. Even when induction has been applied, teacher-fronted instruction and decontextualization have been greatly taken into account. For example, students first practice some separate examples. Next, teachers draw the target form and meaning from the given examples. Then, students continue applying the supplied rules in sentential levels. This reality is due to the pressure of form-based exams on English teachers who have to prepare their students for semester exams and graduation exams all of which emphasize the importance of written tests mainly focusing on isolated grammar. As a consequence of such emphasis on decontextualized and rule-provided grammar instruction, students have spent a great deal of time learning grammar, especially tense and aspect, but they cannot use them accurately.

The error analysis conducted for this study revealed the mistakes that are common among high school students, even those who have studied English tense and aspect for six years (i.e. from grade 6 to 12). That is, for example, the "over-generalized structures" (Richards, 1974) (i.e., we are fly, Look! Somebody spelling, and he is talks quickly). These mistakes may reflect the general results of a separately rule-supplied instruction and of a shortage of contextualized input. Therefore, it is assumed that grammar teaching is biased in favor of form and decontextualization. If true, these could cause a serious drawback for the potential grammar teaching in language education in Vietnam. Based on a general summary of a particular teaching context together with its gap, this project investigated the differences in effectiveness of IEGI compared with that of Direct Explicit Grammar Instruction (DEGI) (e.g., the currently used method) on EFL learners' mastery of tense and aspect. 
Ellis (1997) has mentioned that among many L2 linguistic features, the use of tense is so complicated that learners find difficult to learn. In a survey of many English books for EFL students, textbooks for secondary and high schools in Vietnam, however, tense and aspect occur more frequently than many other structures. The high frequency use of tense can be traced to some of the main reasons as follows: (1) English tense is related to the use of many other structures (i.e., conditional sentence, passive voice, and reported speech) (2) Tense is widely used in both oral and written forms (i.e., daily conversations, newspapers, and essays). Although tenses play a pivotal role in English language, EFL students fail to use them. Therefore, tackling students' common mistakes probably caused by the currently used method, this project largely addressed contextualized use of tense and aspect associated with consciousness-raising tasks for the EG, and to avoid tedious learning conditions, contextualization was also applied for the CG.

\subsection{The Importance of the Problem}

While tenses are crucially important in English language, Decontextualization and rule-provided grammar instruction in most secondary and high schools in Vietnam may generate a huge gap in using English tenses among students. Therefore, this study examined the effects of IEGI (i.e. consciousness-raising tasks) and used tenses as the instructional content. In addition, this project would like to reexamine the results of the previous studies by Fotos and Ellis (1991), Fotos (1993), and Fotos (1994) compared with that of the present research under different settings (i.e. high school learners), grammar structures (i.e. tense and aspects), and kinds of instruments (i.e. oral and written tests). This study also expands the theoretical foundation based on the concept checking through the use of consciousness-raising tasks.

\subsection{Related Literature}

\section{Direct Explicit Grammar Instruction (DEGI)}

Grammar can be taught deductively through direct instruction. Deductively refers to the form of explicit explanations of grammatical structures provided to learners orally or in writing (Ellis, 1997). It helps the teacher save time for the class, but a major drawback is that the repeated rule presentations of grammar structures may make students lose their sense of discovery, and that easily leads to the state of tediousness. In this method, "students are supplied with a rule (or, perhaps, part of a rule) which they then apply, complete or amend in a task that requires them to analyze data that illustrate its use" (Ellis, 1997, p. 86). For example, students may be given a rule about the simple past tense with a number of sentences and instructed to use the rule to recognize which of the sentences are grammatical and which are ungrammatical. Learners are therefore quite dependent on the teacher's explanations or provision of grammar rules.

\section{Indirect Explicit Grammar Instruction (IEGI)}

While direct explicit grammar instruction refers to the use of deduction, indirect explicit grammar instruction favors induction or the learners' discovery of the grammatical rules through tasks and therefore does not involve giving grammatical explanations (Ellis, 2008, p. 159). It implies a problem-solving approach in which "students are provided with data which illustrates the use of a specific grammatical structure which they analyze to arrive at some generalization that accounts for regularities in the data" (Ellis, 1997, p. 86). For example, students may be given a reading passage containing some illustrations of the use of the simple present and the present continuous tenses and are required to 'identify' the verbs in both tenses and then build a 'rule' to explain their different functions. Briefly, from the given input and tasks, learners have to construct the grammar rules for themselves.

The tasks commonly used in this approach are indirect consciousness-raising tasks which aim: "to help learners construct their own explicit grammar of the target language and to encourage communication in the L2 between learners" (Ellis, 1997, p. 87). They are called either pedagogic activities (Ellis, 1997, p. 160) or structured input tasks (Thornbury, 2005, p. 40); or discovery tasks (Ellis, 2008, p. 165). These tasks differ from direct consciousness-raising tasks whose goals are explicit knowledge of grammar rules and which include some "meta-lingual knowledge" instructed by "direct explanation-of the kind used in the grammar translation method" (Ellis, 1997, p. 160). The goals of direct and indirect consciousness-raising tasks have been denoted. Below are some suggested ways to design and apply these tasks.

The design, application, and limitations of indirect consciousness-raising tasks are worth considering. Ellis (1997) has suggested some types of operations that can be performed on the data: (1) identification, (2) Judgment, (3) completion, (4) modification, (5) sorting, and (6) matching. There are also other factors to be noticed. This task type can be performed by individuals, pairs or small groups. To accomplish the tasks, both oral and written forms are advised to use and learners can use their first language or the second language (L2) (pp. 161-162). 
Simultaneously, Hinkle (2008, p. 185) has pointed out that these tasks enable learners to examine how grammatical structures are applied in real contexts and raise their implicit and explicit knowledge of grammar through the use of authentic language. In contrast, they have their own limitations; they may not be appropriate to beginners or young learners (Ellis, 1991 and Sheen, 1992, as cited in Ellis, 2003, p. 166).

\section{Prior Research}

There has been considerable research on direct and indirect explicit instructions by Fotos and Ellis (1991), Fotos (1993), and Fotos (1994). The studies of the effectiveness of direct and indirect explicit grammar instruction can be summarized as follows. First, noticing the target structures in the comprehensible input has been claimed to be indispensable for the language learning to take place. Noticing has been elaborated into two versions of tasks: grammar consciousness-raising tasks and consciousness-raising communicative tasks. Second, both direct and indirect grammar instruction can facilitate the acquisition of the target forms rather than the communicative tasks without specific attention to grammar. Third, concerning proficiency test types, although grammaticality judgment test has been called into question, it is still the main test type to be used with other types such as sentence production types, in which the performance of the target forms occurs in free-defined contexts (i.e. oral and written tests).

However, as Ellis (2006) summed up the issues of grammar instruction in his article "Current Issues in the Teaching of Grammar," the results of the studies on deductive and inductive grammar teaching "have been mixed" (p. 97). He expounded on the subject as follows. While some researchers maintained that deductive approach has proved to be effectual, others claimed that no significant difference in effectiveness between the two approaches has been found. And to some others, inductive approach has been found to be more effective.

Given such a situation, what happens if grammar conscious-raising tasks are used with teacher's feedback in a sequence different from what has been found in the PPP in which the target structure is presented in the first P under the form of teacher-fronted presentation? Is there a possibility of integrating the grammar consciousness-raising tasks and consciousness-raising communicative tasks? These questions, therefore, have provided the basis of the present study to be carried out. It attempts to find out whether or not a mixed model of indirect-direct explicit grammar teaching can enhance noticing of the form and the retention of the target structure.

\subsection{Research Questions (RQ) and Hypothesis $(H)$}

RQ1: Is there a significant difference between the experimental group and the control group as a result of the IEGI treatment (as compared with the DEGI)? If so, to what extent does the experimental group outperform the control group in terms of:

- grammatical comprehension (accuracy)?

- grammatical production (use)?

H1: It may be hypothesized that the experimental group, which received the IEGI, will significantly surpasses the control group in the RAT, the GT, and the speaking test after the treatment.

RQ2: Is there a positive relationship between the knowledge of grammar rules and the application of those rules in receptive and productive practice?

$\mathrm{H} 2$ : There will be an observable (statistically significant) connection between the knowledge of grammar rules acquired and the application of those rules in their subsequent use. In other words, rule mastery will assist students in using tenses more accurately than those with no rule mastery.

RQ3: To what extent do the experimental students agree with the IEGI?

H3: with reference to learners' views on IEGI, there will be a relationship between how a student performs and what the students thinks about the IEGI. It may be hypothesized that students who are under average or less able students in being familiar with the provision of grammar rules will not favor the IEGI as much as the average and above average students, concerning the limitations of the consciousness-raising tasks discussed in Ellis (2003).

\section{Method}

\subsection{Pilot Stage and Treatment}

This project used a trial teaching practice and re-administration method to pilot the instruments before the experiment conducted. The three procedures are as follows: 


\section{Pre-stage}

The teaching plans and instruments were first piloted for their reliability. The trial teaching was conducted with a class of 31 students who did the pilot test before the treatment phase. First, the teacher had four periods (180 minutes) of trial teaching. Then, she interviewed two students: a male and a female to get their feedback on the method she had applied. She asked them about the content of the two lessons and the usefulness of consciousness-raising tasks to check their understandings. She also asked them some questions included in the questionnaire to get their feedback on the method as it was implemented. She recorded the whole trial and interviews with an MP3 player and took some necessary notes so that she could have specific information to adjust the lesson plans and the instruments if needed.

\section{Implementation-stage}

The teaching phase lasted eight weeks, each had 90 minutes. Students in two classes received the same amount of time, contextualized input, and practice. Although control students had the same input as that of the counterparts, the techniques were different (i.e., no interaction to raise students' notice of grammatical forms). In addition, while deductive subjects were presented and explained the grammar rules, the inductive students were engaged in 'rule-searched' tasks. Then they were given feedback and confirmation of what they had searched before. Following are detailed descriptions of instructions.

The experimental subjects first read or listened to a passage and interacted with the teacher based on the given examples of grammar presentation in the text (i.e., teacher may ask students about the target form, the way it works, etc.) In this way, they are stimulated to notice a grammatical feature designed to lead them to its understanding because the text is contextualized and learners have opportunities to be aware of the meaning to operate the grammar structure. Instead of receiving grammatical rules passively, the inductive group was engaged in rule-searched condition tasks (i.e. students work in pairs and groups) to find out the form and meaning of the target structures. Then, the teacher checked their understanding and giving feedbacks in order to combine the development of knowledge about problematic L2 grammatical features with the provision for meaning-focused use of the target language. The procedures were divided into 5 stages, adapted from Harding and Taylor (2005) and Cunningham and Moor (2005): (1) lead-in, (2) providing input, (3) consciousness-raising tasks, (4) checking and summarizing, and (5) practice. In the last step, practice, students did some given activities by themselves; the teacher did not interfere with students' practice.

On the other hand, the direct explicit group received different instruction in step 3; they were presented and explained the grammar rules. This group was also exposed to similar input (i.e., a reading/listening activity) as that of the inductive group (step 2). Although students had the same input as that of the experimental group, the techniques were different (i.e., no interaction to raise students' notice of grammatical forms).

\section{Post- stage}

Students of both classes did the post-tests after the treatment: the rule analysis test and the grammar test. Then, they took part in the oral test the following week, and a month after that, they continued doing the delayed written test. The main purpose of these tests was to check the retention of the grammar structures and the correlation between the grammar rules and the use of these structures in a free-defined context.

\subsection{Participants}

The ninety-four participants in this research project were students whose English levels were pre-intermediate of the 'basic' cohorts (as categorized by the high-school). Every class in this section had an average level of English; they were not good at and did not major in English. Two classes whose English grades in the second semester exam were relatively equal were selected. Specifically, each class had seven students getting the under-average scores and the other forty students, achieving fair, good, and excellent grades, were nearly the same. One of the two classes was designated as an experimental group. This class, which had 47 members, was more heavily weighted towards females (33) than males (14); the other was treated as the control group having 47 students, 26 of whom were females and the remaining (21) were males.

\subsection{Sampling Procedures}

Although non-probability sampling is not the best sampling procedure for respresentativeness, it is the most common form of sampling in educational research. In this study, the target sample was EFL high school students in two classes that were selected conveniently among the population of 25 Grade-11 at Marie Curie High School in Ho Chi Minh City-Vietnam. 


\subsection{Data Type}

The study used a quantitative method with different sources of data related to the objectives and research questions. The assessment instruments that were involved in this study were a rule analysis test (RAT), a grammar test (GT), an oral test (OT), a written test (WT), and a survey questionnaire. The first three tests were included in the pretest to measure their level on the criterion variables of analysing rules of tenses (i.e., RAT), applying these rules in a pre-defined context (i.e., GT) and a free-defined setting (i.e., OT), but four kinds of tests were administered in the posttest; the written test was conducted in a delayed post-test with the main purpose to check the retention of the grammar structures in productive practice and the correlation between the grammar rules acquired and the use of these structures in the productive use. The pretest was administered a week before the treatments. The post-test including the RAT and the GT was conducted one day after the two instructional methods implemented, and the OT was administered a week after that. The questionnaires were distributed to the experimental group after finishing the treatment. Finally, the delayed post-test was given a month after the speaking section took place.

Each type of measuring instrument which has its own forms and purposes plays a key factor in determining the quality of a piece of educational research. Therefore, this study took great care of both of those two aspects. The RAT and the GT were designed in both subjective and objective forms. The subjective items were for measuring the students' ability to avoid errors in using tenses and the objective form was used to check the learners' recognition of tenses. Furthermore, the administration of the oral and written tests was to examine whether the rules acquired could remain and produced. In these two tests, students were given a context that was not a pre-defined setting as that of the grammar test. All tests were designed as a means not only to assess the proficiency level of the targeted structure but also to measure knowledge of grammatical form, meaning, and use. In addition, consideration was given concerning the usefulness of the instruction and many other components related to the objectives of the study. The questionnaire was used to serve a secondary aim in this study which was to explore the extent of students' agreement on the treatment.

\section{Results}

From the major objectives of the three research questions, Independent Sample T-tests were first applied to analyze the statistical differences in the mean scores of the pre- and post-stages of the rule analysis test (RAT), the grammar test (GT), and the oral test (OT). In other words, the differences between the two groups were evaluated for statistical significance to answer research question 1 (RQ1). Next, the correlation coefficient was computed to evaluate more fully the relationship between the RAT and the GT, the OT, and the WT as a means of answering RQ2. Finally, simple frequencies and percentages are presented of the experimental learners' responses of the questionnaires to respond to RQ 3. The minimum alpha level accepted for declaring statistical significance for the difference between means used in this research was $\mathrm{p}<.05$.

\subsection{Summary of the T-test Results (RQ1)}

Table 1.

\begin{tabular}{llllllll}
\hline Test & Group & Number & Mean & SD & $T$ & Df & Sig. (2-tailed) \\
\hline RAT & Group 1(EG) & 47 & .767 & .178 & 2.44 & 92 & $\mathbf{. 0 1 6}$ \\
& Group 2 (CG) & 47 & .680 & .169 & & & \\
GT & Group 1 & 47 & .624 & .178 & .584 & 92 & $\mathbf{. 5 6 1}$ \\
& Group 2 & 47 & .602 & .175 & & & \\
OT & Group 1 & 47 & 5.93 & 1.08 & 2.75 & 92 & $\mathbf{. 0 0 7}$ \\
& Group 2 & 47 & 5.39 & .783 & & & \\
\hline
\end{tabular}

The large difference of the two means in the RAT resulted in the Sig. (2-tailed) value of .016; $p<.05$. These figures demonstrate that Group 1 performed significantly better at analysing grammar rules than Group 2 . Accordingly, it is strongly acknowledged that this result satisfied the proposed hypothesis.

It is clear that from the GT that the differences between the two groups were not large enough to reject the null hypothesis; the $P$ value was .561, higher than the set up level .05 . Unexpectedly, these results were found to be insignificant.

In the OT, the mean of Group 1 (EG) was 5.93, higher than that of Group 2 (CG) which was at 5.39. This difference resulted in a $t$ score with a significant value of .007 ; i.e., less than the .05 alpha levels set for this project. This finding obviously demonstrates that students of the experimental group were better at using English tenses in oral form than those of the control group after the experiement as previously hypothesized. 
In Summary, both groups increased their grammatical competence and performance. However, the EG statistically surpassed the CG in the analysis of grammar rules and the oral proficiency, except for the use of grammar structures in a pre-defined context (grammar test).

\subsection{Correlation Results for the EG and the CG (RQ2)}

There is a positive relationship between the RAT and the other three tests: GT (.513), OT (.790), and WT (.855) among the experimental learners and all were found to be statistically significant; the magnitudes of the correlation coefficients were large enough to warrant a conclusion of statistical significance and thus provide a meaningful interpretation for the results. However, the connection between the RAT and the GT was not as strong as the other two correlations since its value was only .513.

In addition, there was a close connection between the grammar rules acquired and the productive outputs for the control group as well. Although the correlation figures of the OT (.661), WT (.818) were all statistically significant, the relationship between the RAT and the GT was weak; its correlative value was .472.

The statistics revealed a high correlation between the grammar rules acquired and their subsequent use in the oral and delayed written tests of both groups although the correlative figures of the CG were lower than that of the EG.

\subsection{Attitudes towards the Instruction (RQ3)}

The three main themes of the questionnaire were approach preferences including four scales (i.e., very much, much, not much, not at all) ( $\mathrm{M}=2.82)$ and favourable and unfavorable reasons with five scales of agreement or disagreement (i.e., totally agree, agree, not sure, disagree, totally disagree). Reasons of reference were much higher than that of unfavorable reasons, $\mathrm{M}=4.1$ and $\mathrm{M}=2.7$ respectively. This indicates that the experimental subjects showed their preferential attitudes towards the instruction.

\section{Discussion and Conclusions}

\subsection{Discussion}

Concerning RQ1, the statistical difference between the experimental group and the control group in grammatical comprehension (accuracy) and grammatical production (use) may be explained as follows:

\section{Rule Comprehension}

The fact that Group 1 outperformed Group 2 in the rule analysis test (RAT) suggests that the consciousnessexplicit grammar instruction exemplified through consciousness raising tasks may provide students with an opportunity to "develop explicit L2 knowledge for themselves" (Ellis, 1997, p.160). This kind of approach is different from the model of education in which a teacher transmits a grammatical structure via direct explanations - direct explicit grammar teaching, which "may fail to engage some learners in taking active responsibility for their own learning" (ibid). Second, the problem-solving tasks, consciousness-raising tasks, might help learners to recognize with more awareness new items processed during the input (Leow, 2007). This clearly improves their long-term memory for later retention. Third, a discovery approach helps students enhance their analytical abilities and understand the target features effectively rather than relying on memorization as what might be found in the control group.

What has been discussed is concerned with the fact that the experimental group significantly outperformed the control group in terms of understanding rules. However, how could one explain the fact that the experimental group did not surpass the control group with reference to grammar test gains, but outdid the control group in terms of oral production? To answer this question, one might be inclined to think of the following issues.

\section{Receptive Practice}

The grammar test (GT) administered might be incorporated with the features of receptive practice in which students had to perform some activity to demonstrate they had understood sentences including the target structure. As such, the GT is a kind of test that the researcher used to assess whether or not the students were able to use (practice) the structure learned (i.e. present tenses). Given this context, some explanations related to why the experimental group did not significantly outperform the control group are offered as follows:

Firstly, memorization can be an explanation for the fact. Through the GT, students are likely to be exposed to manipulate L2 input that provides "not only various exemplars of targeted L2 forms or structures upon which learners' attention to (and/or awareness of) is directly or indirectly premised but also some form of opportunity to perform a limited productive or non-productive task" (Leow, 2007, as cited in Dekeyser, 2007, p. 21). In this kind of test, the control group could perform quite well because they might rely on the 'rules of thumb' or 
guidelines prescribed through the teacher's direct explicit grammar instruction. The students might rely on what the teacher highlighted or stressed during the lecture and did not have to make use of any other options before deciding on a certain choice to satisfy the requirements of the task. Clearly, they might have benefited from the combination of contextualized input and the teacher-fronted instruction. In direct explicit instruction, the teacher raised the students' notice of grammar structures though comprehensible input together with careful explanation and provision of the target structures. This may suggest that students might have had good conditions to take the grammar rules in and practice them. Thus, it is likely that this process had a great influence on the learners so they could give out correct immediate outcomes.

The experimental group, on the contrary, probably had to consider different options before making up their minds as a result of the different types of learning involved in the consciousness-raising tasks (discussed in detail below). They had to re-analyze and to struggle with different options before settling on a certain choice. Although the students were given feedback after searching rules, they might be assumed to be still in the process of restructuring the target structures at the time they did the grammar test. This may explain why the experimental students, especially less able ones, did not have a clear-cut decision to do the grammar test. In other words, they had a 'fuzzy' state of mind because they might have had to consider different options that might have occurred in their mind. This may be supported by one of the noted limitations of the consciousness-raising tasks methods i.e., it is not suitable for low level learners, as stated by (Ellis, 1991 and Sheen, 1992, as cited in Ellis, 2003, p. 166).

Secondly, the insignificant difference may be the result of a delayed effect. According to Thornbury (2005), a consciousness-raising task does not give immediate or direct effects. He points out that it has "a slow-release pill that affects the system over time; i.e., the effects may not even be very direct" (p. 38). From his point of view, the same scores of the two groups strongly suggest that this task releases results slowly and indirectly. Inferentially, the result of the GT concerning the grammatical comprehension indicates that the two instructional approaches were equally effective.

In brief, 'learning from hearing' and 'learning by doing' resulted in similar outcomes in the receptive stage. This result reinforces the findings of the previous research performed by Fotos and Ellis (1991) and Fotos (1993, 1994) regarding the acquisition of explicit grammatical knowledge. However, to adequately address the issue of students' grammatical performance and reflect the real context of grammar teaching, this study shows an additional effect of the grammar teaching approach.

\section{Productive Practice}

Back to the question above "how can one explain the fact that the experimental group outdid the control group in oral production?" Here are some possible explanations.

First, implicit knowledge may play a role in determining the fact that the experimental group significantly outperformed the control group in the oral post-test. One may wonder why implicit knowledge (unconscious knowledge) may have its part in the context where the focus is on explicit knowledge (conscious knowledge). Actually, the researcher is in agreement with DeKeyser (1998, cited in Randall, 2007) when he points out that, there is no distinction between explicit and implicit knowledge; they are related to each other. N. Ellis, based on a cognitive and neurological viewpoint, contends that "conscious processing acts as a necessary interface between input and formation of implicit knowledge. Attention to grammatical form provides exactly that focus on form which can lead to successful implicit knowledge" (2005, cited in Randall, 2007, p.163). Conscious-raising in the study could provide opportunities for the students to focus on form which might have acted as a latent factor that could assist them in their oral performance.

Second, the depth of processing (Randall, 2007) is likely to be another factor that accounts for the better performance of the experimental group in the oral test. Consciousness-raising tasks together with teacher's confirmation did provide a good context for meaningful 'repetition' or processing. The tasks reflect Eysenck's \& Eysenck's viewpoints (1980, discussed in Randal, 2007, p. 135) on tasks. They suggest it would be better to help students recognize words used in tasks which involve either semantic processing or distinctive features than to ask them to recognize words which are used in a shallow, non-distinctive, non-semantic processing task. In fact, the consciousness-raising tasks are an elaboration of the higher order of Gagné's hierarchy of learning: problem-solving. In this type of learning, before students are able to solve problems, they should have had some time of noticing, chaining, associating, and theorizing. The processes will be manipulated by the working memory which helps boost the automaticity in the long-term memory (Gagné, 1985, discussed in Randall, 2007, p.138). The in-depth processing resulted from the tasks might have helped the experimental students' long-term memory which create an added impetus for their better performance than that of the control ones in the oral test. 
Back to RQ2, the significant difference between knowledge of grammar rules and grammatical production of the two groups can be interpreted as follows:

Although there was a positive relationship between the knowledge of grammar rules and grammar production found in both groups (i.e., the experimental and control groups), the more meaningful correlation of the experimental group might suggest some issues worth discussing. First, the indirect effects of consciousness-raising tasks may explain this fact. The result confirms what Ellis (1993a) and Rutherford and Sharwood Smith (1988, as cited in Larsen-Freeman, 2003, p. 91) have contended the role of consciousness-raising tasks in language teaching. According to Ellis, when noticing a structure, learners are supposed "to store a trace, which will help them to process the structure more fully at a subsequent time." Rutherford and Sharwood Smith also point to the fact that if students are made aware of the target language rules, their language acquisition will be facilitated. The positive correlation between the comprehension rules and the oral and written production of the task group is therefore supported.

Second, the high correlation coefficient between the grammar rule knowledge and grammatical production suggests the superior role of consciousness-raising tasks (in comparison with the traditional way of presenting rule-teacher-fronted instruction). The high level of input (noticing, interacting, associating, group work) inherent in the tasks may have created a good condition for the working memory (i.e. short-term memory) to be translated into the long-term memory, which probably leads to the high performance of the group in question as mentioned.

Third, the belief that grammar is the basis for other kinds of skills to grow might be reconsidered. From this study, the positive correlation found in the two groups between the grammatical knowledge and grammatical production confirms Celce-Murcia's ideas (1991) on the role of grammar teaching. She has stated that "grammar is a tool or resource to be used in the comprehension and creation of oral and written discourse rather than something to be learned as an end in itself" (p. 466). For, in this case, learning grammar may help boost acquisition.

\section{RQ3: Attitudes towards the consciousness-raising task}

The fact that most learners in the experimental group $(59.6 \%$; $\mathrm{n}=47)$ had positive attitudes towards the grammar instruction, compared with those who have negative ideas $(40.4 \%$; $n=47)$ towards the method, confirms what has been mentioned above with reference to the advantages of consciousness-raising tasks; see Ellis (1993a, 1997, 2008), and Hinkle and Fotos (2008). However, what is worth discussing is the dividing attitudes of those learners who have negative ideas (i.e. those who disliked the method) towards the instruction.

More than half of the learners, who disliked the method because they thought that it did not enhance their analytical skills, remained agreeable to the features of consciousness-raising tasks. Around 65 percent of the learners in the 'negative' group did agree that the tasks improved their active work, attention, and memory of the targeted structures and interaction in pairs work and group work. This confirms what Harmer (2007, p.43) reports as the advantages of these cooperative activities, which enable students to have more chances for greater independence. Not to mention the positive attitudes of the 'positive' group, the fact found in the 'negative' group does support what has been claimed about the positive effects of the consciousness-raising tasks. Indeed, the frequency of input (i.e. noticing, interacting, associating, and pair/group work) is quite high, as compared with the only input resulting from the single channel from the teacher, in which the students just act as a receptacle of what the teacher conveys. Thus, the highly frequent input does create a large number of opportunities to be impressed more deeply into the long-term memory of the students. What has been found concerning the students' attitudes, namely what has been observed among the 'negative' ones, towards the consciousness-raising task, has provided a good basis for supporting what has been advocated by theorists and practitioners about consciousness-raising tasks.

\subsection{Conclusions}

The findings demonstrate that the IEGI can have great contributions to enhancing learners' rule comprehension of English tenses as well as the use of tenses in productive practice (i.e., the oral test) which took place a week after the treatment. Thus, it is likely that attention could play a crucial role for long-term memory storage of L2 information to take place (Leow, 2007) and that the indirect effects of consciousness-raising tasks (Thornbury, 2005) did affect learners' subsequent use of tenses.

In addition, although the lack of dissimilarity (from the results of this study) concerning the use of tenses in a pre-defined context suggests the equal effect of consciousness-raising tasks and the teacher-fronted instruction, the fact that there was a correlation between the mastery of grammar structures and the use of grammar (i.e. tense and aspect in this study) in the pre-defined (i.e., receptive) setting and free-defined (i.e., productive) 
contexts may lead to the validation of the cause and effect of the acquisition of grammar rules and the use of these grammatical aspects in receptive and productive stages. Also, the results from the delayed written test adequately demonstrate the capability of IEGI in helping students retaining the grammatical structures.

What is worth mentioning from this study is the students' agreement on the positive effect of IEGI. Even those students who were not in favor of the instruction method took a positive attitude toward the usefulness of the tasks. Therefore, IEGI as exemplified through the concept checking-based consciousness -raising tasks is worth revisiting in the context of grammar teaching given the results yielded.

\section{Implications}

The study has provided some insights into indirect explicit grammar instruction as operationalized through consciousness-raising tasks. The following are some implications that can be drawn from this study.

First, to teach grammar effectively, namely during the presentation stage, teachers are advised to use consciousness-raising tasks. This suggests that although concept telling (i.e. teacher-fronted instruction) may be effective, it would not provide long-term effect on the production of the targeted structures as effectively as what would be found with consciousness-raising tasks or concept checking.

Second, although consciousness-raising tasks would require more work and effort from teachers in terms of task preparation and cost (i.e., handouts photocopying, etc.) what would be acquired from this method is worth giving attention to.

Third, in addition to the common characteristics of the tasks, teachers need to pay much attention to the logic and organization of the tasks to suit a variety of learners. In other words, tasks should be well-designed and carefully-organized so that even less competent students can be confident to join in performing the tasks together with the competent ones.

Fourth, since Vietnamese students have been familiar with the concept-telling method (in teaching grammar), they should be prepared to get accustomed to those factors of the new aspects such as individual work, team-working, critical thinking operation. Most importantly, they should not expect the right answer from the outset. For throughout the tasks, they are required to provide answers, which they do not have enough courage to offer if they are much afraid of 'losing face'. Thus, it is important to prepare students' state of mind before engaging them into the tasks.

Fifth, teacher's rule summary after pairs'/groups' discussion is worth considering because consolidation will provide a good chance to arouse students' noticing the structures in the input through the tasks. This will give learners opportunities to double check their self-discovered rules and to make the grammar rules more engraved in their memory.

Finally, the proficiency level should be a factor that teachers have to take into consideration when using this way of teaching. Teachers may adjust the requirements to suit students' level of proficiency. That is, for instance, instead of asking students to use English while performing the tasks, teachers may let them use both English and their first language as suggested by Ellis (1997). This suggests that teachers should be alert in organizing group work. The balance students' various levels in groups may result in good effects because of individual contribution and mutual assistance between less able and able students. Students of lesser proficiency could be more confident by the help of their friends or find little difficulty in asking their friends for help. In contrast, good students might have compatible conditions to review the grammar structures by helping their friends. If not, less competent students may become demotivated if they are put into one group or vice versa.

\section{Acknowledgements}

This study was completed with many people's assistance, support, and co-operation. My heartfelt thanks will send to those who have contributed to the completion of this project.

First, I send my greatest gratitude to my supervisor, Dr. Hương Thu Nguyễn, for his valuable guidance, advice, encouragement, and comments. In addition to his knowledgeable and spiritual support, he also provided me with useful sources of materials in language teaching methodology as well as in doing research. Next, I am grateful to my colleagues, Ms. Loan Tuyết Lý and Ms. Linh Phạm Phương Trần, for their enthusiastic contributions to the pilot stage of teaching and assessing instruments. Many thanks are also given to two groups of students who have joined in the study, for their great efforts to complete various tests and questionnaires. Then, my particular gratefulness is sent to all of my lecturers, who have laid foundation for this thesis; I am greatly indebted to Dr. Dennis Berg and Dr. Philip McKinney for their unending enthusiasm to read the project and give lots of valuable suggestions. Finally, my special thanks to Mr Tâm Thanh Trần, who has guided me to operate and analyze the 
SPSS statistics, is my colleague and my husband as well.

\section{References}

Celce-Murcia, M. (1991). Grammar pedagogy in second and foreign language teaching. TESOL Quarterly, 25, 459-480. Retrieved from http://www.hpu.edu/Libraries_HPU/Files/TESOL/TQD/VOL_25_3.pdf http://dx.doi.org/10.2307/3586980

Cunningham, S., \& Moor, P. (2005). New cutting edge. Harlow: Longman.

Ellis, R. (1997). SLA Research and language teaching. Oxford: Oxford University Press.

Ellis, R. (2003). Task-based language learning and teaching. Oxford: Oxford University Press.

Ellis, R. (2006). Current issues in the teaching of grammar. TESOL Quarterly, 40, 83-107. Retrieved from http://faculty.weber.edu/tmathews/SLI/Readings/Ellis\%202006.pdf. http://dx.doi.org/10.2307/40264512

Ellis, R. (2008). Grammar in language teaching. In E. Hinkle, \& S. Fotos (Eds.), New perspectives on grammar teaching in second language classrooms (pp. 13-15). New York: Routledge.

Ellis, R. (2008). Methodological options in grammar teaching materials. In E. Hinkle, \& S. Fotos (Eds.), New perspectives on grammar teaching in second language classrooms (pp. 155-176). New York: Routledge.

Fotos, S., \& Ellis, R. (1991). Communicating about grammar: A task-based approach. TESOL Quarterly, 25(4), 605-628. Retrieved from http://www.hpu.edu/Libraries_HPU/Files/TESOL/TQD/VOL_25_4.pdf

Fotos, S. (1993). Consciousness raising and noticing through focus on form: Grammar task performance versus formal instruction. Applied Linguistics, 14(4), 386-407. Retrieved from http://applij.oxfordjournals.org/content/14/4/385.short

Fotos, S. (1994). Integrating grammar instruction and communicative language use through grammar consciousness-raising tasks. TESOL Quarterly, 28(2), 323-351. Retrieved from http://www.jstor.org/stable/3587436. http://dx.doi.org/10.2307/3587436

Harding, K., \& Taylor, L. (2005). International express. Oxford: Oxford University Press.

Harmer, J. (2007). How to teach English. Oxford: Pearson Longman.

Hinkle, E. (2008). Teaching grammar in writing classes. In E. Hinkle, \& S. Fotos (Eds.), New perspectives on grammar teaching in second language classrooms (pp. 181-198). New York: Routledge.

Larsen-Freeman, D. (2003). Teaching language: From grammar to grammaring. Heinle: Newbury House.

Leow, R. P. (2007). Input in the L2 classroom: an attentional perspective on receptive practice. In R. M. Dekeyser (Eds.), Practice in a second language: perspectives from applied linguistics and cognitive psychology (pp. 21-50). Cambridge: Cambridge University Press.

Randall, M. (2007). Memory, psychology and second language learning. Amsterdam: John Benjamins.

Richards, J. C. (1974). A non-contrastive approach to error analysis. In J. C. Richards (Eds.), Error analysis: Perspectives on second language acquisition (pp. 172-188). Lowe \& Brydone: Longman.

Thornbury, S. (2005). Uncovering grammar. Oxford: Macmillan Education. 